\title{
Arabidopsis Bax Inhibitor-1 inhibits cell death induced by pokeweed antiviral protein in Saccharomyces cerevisiae
}

\author{
Birsen Çakır ${ }^{1,2, *}$ and Nilgun E. Tumer ${ }^{1}$ \\ ${ }^{1}$ Biotechnology Center for Agriculture and the Environment and the Department of Plant Biology and Pathology, Rutgers University, \\ New Brunswick, NJ 08901-8520, USA. \\ ${ }^{2}$ Department of Horticulture, Faculty of Agriculture, Ege University, Izmir, Turkey. \\ * Corresponding Author: Birsen Çakir, Department of Horticulture, Faculty of Agriculture, Ege University; Izmir, Turkey; Tel: +90 232 \\ 3112633; Fax: +90 232 3881865; E-mail: birsencakir@hotmail.com
}

\begin{abstract}
Apoptosis is an active form of programmed cell death (PCD) that plays critical roles in the development, differentiation and resistance to pathogens in multicellular organisms. Ribosome inactivating proteins (RIPs) are able to induce apoptotic cell death in mammalian cells. In this study, using yeast as a model system, we showed that yeast cells expressing pokeweed antiviral protein (PAP), a single-chain ribosome-inactivating protein, exhibit apoptotic-like features, such as nuclear fragmentation and ROS production. We studied the interaction between PAP and AtBI-1 (Arabidopsis thaliana Bax Inhibitor-1), a plant anti-apoptotic protein, which inhibits Bax induced cell death. Cells expressing PAP and AtBI-1 were able to survive on galactose media compared to PAP alone, indicating a reduction in the cytotoxicity of PAP in yeast. However, PAP was able to depurinate the ribosomes and to inhibit total translation in the presence of AtBI-1. A C-terminally deleted AtBI-1 was able to reduce the cytotoxicity of PAP. Since anti-apoptotic proteins form heterodimers to inhibit the biological activity of their partners, we used a coimmunoprecipitation assay to examine the binding of AtBI-1 to PAP. Both full length and C-terminal deleted AtBI-1 were capable of binding to PAP. These findings indicate that PAP induces cell death in yeast and AtBI-1 inhibits cell death induced by PAP without affecting ribosome depurination and translation inhibition.
\end{abstract}

\author{
doi: $10.15698 /$ mic2015.02.190 \\ Received originally: 09.06.2014; \\ in revised form: 30.12.2014, \\ Accepted 27.01.2015, \\ Published 02.02.2015.
}

\begin{abstract}
Keywords: ribosome inactivating proteins (RIPS), pokeweed antiviral protein (PAP), Arabidopsis thaliana Bax Inhibitor-1, apoptotic-like cell death.
\end{abstract}

\begin{abstract}
Abbreviations:
$P A P$ - pokeweed antiviral protein, $P C D$ - programmed cell death, RIPS - ribosome inactivating proteins, SRL - sarcin/ricin loop.
\end{abstract}

\section{INTRODUCTION}

Ribosome inactivating proteins (RIPs) that are toxins isolated from plants, fungus, or bacteria catalytically inactivate eukaryotic as well as prokaryotic ribosomes by removing single adenine residues from the universally conserved sarcin/ricin loop (SRL) of the large rRNA [1-4]. In addition to rRNA $\mathrm{N}$-glycosidase activity, RIPs have broad spectrum antiviral activity against RNA and DNA from plant and animal viruses $[5,4]$.

Pokeweed antiviral protein (PAP), a single chain type I RIP, isolated from leaves of pokeweed plants (Phytolacca americana), removes specific adenine and guanine residues from the SRL $[1,6,7]$. This enzymatic activity interferes with the binding of eEF-2 (elongation factor 2) thereby inhibiting protein synthesis at the translocation step [8, 9]. PAP has antiviral activity against animal and plant viral pathogens including HIV, poliovirus, herpes simplex virus, influenza, potato virus $X$, and BMV [10-14]. Hudak et al. [7,
15] demonstrated that PAP could also inhibit translation of mRNAs and viral RNAs that are capped by binding to the cap structure and were depurinating the RNAs downstream of the cap. It has been reported that the antiviral activity of PAP can be separated from rRNA depurination [16]. These results suggested that PAP might interfere with virus replication by a mechanism other than host ribosome inactivation. One possible mechanism is that RIPs might target not only the SRL but also the nucleic acids of invading pathogens. Wang and Tumer [17] showed that PAP cleaved double stranded supercoiled DNA using the same active site required for ribosome depurination. Similar activity of other RIPs on supercoiled double-stranded DNA templates was observed with dianthin, gelonin, cinnamo$\min$ and saporin [18-20].

Besides inhibition of protein synthesis, RIPs are able to induce apoptosis in different cells [21-25]. Griffiths et al. [26] demonstrated that ricin and abrin induced apoptosis 
in mammalian cells. Many other bacterial as well as plant toxins were also found to induce apoptosis in mammalian cells [21-23, 25, 27-29]. Work from our laboratory has shown that the precursor form of the A chain of ricin (preRTA) in yeast cells induced the onset of apoptotic markers such as nuclear fragmentation, chromatin condensation, and accumulation of reactive oxygen species [30]. The ability to depurinate ribosomes and inhibit translation does not always correlate with ricin-mediated cell death [30]. The cell death induced by the RIPs, such as ricin, modeccin, diphtheria toxin and pseudomonas toxin involves caspases $[31,32]$. In addition, trichosanthin, a type I RIP, has been shown to induce apoptosis by high levels of ROS production in human choriocarcinoma cells [33].

Apoptosis is co-regulated by the conserved family of $\mathrm{Bcl}-2$ related proteins, which includes both antiapoptotic (e.g., $\mathrm{Bcl}-2$ and $\mathrm{Bcl}-\mathrm{XL}$ ) and proapoptotic (e.g., bax and bak) members. A human Bax inhibitor-1 (BI-1) gene was isolated as a suppressor of bax induced cell death in yeast. BI-1 is evolutionary conserved ER protein that suppresses cell death in plants, yeast and animal cells [34]. Recently, a yeast $\mathrm{BH} 3$ domain containing protein ( $\mathrm{Ybh} 3 \mathrm{p}$ ) was identified and regulates the mitochondrial pathway of apoptosis [33]. Interestingly, overexpression of Ybh3p sensitizes yeast cells to apoptotic stimuli, while its knockout reduces cell death [33]. Although no homologs of Bcl-2 family proteins have been identified in plants, $\mathrm{BI}-1$ is widely conserved in organisms, including Caenorhabditis elegans and Xenopus leavis [34]. Subsequently, BI-1 homologs from plants have been isolated [34-39]. AtBI-1, a plant homologue of $\mathrm{BI}-1$ from Arabidopsis thaliana suppresses Bax and $\mathrm{H}_{2} \mathrm{O}_{2}$ mediated cell death in yeast, animal, and plant cells [40-42]. AtBI-1 is mainly localized in the ER, contains 6 or 7 transmembrane domains with highly conserved C-terminal region that is required for the suppression of cell death [41]. Overexpression of AtBI-1 was shown to suppress cell death induced by biotic and abiotic stresses [36, 41-42]. Overexpression of Bax in plant cells causes ROS generation, organelle disruption, and ion leakage from cells [44, 45] and AtBI-1 prevents ion leakage, but not ROS generation, when overexpressed together with Bax in Arabidopsis [43]. Recently, Watanabe and Lam [46] demonstrated that AtBI1 played an important role in attenuation of ER stressinduced cell death [46-47]. Another plant BI-1 homologue inCapsicum annuum has been shown to be induced under various abiotic stresses including high salinity, heavy metal stresses and ABA [48]. Moreover, it was demonstrated that AtBI-1 interacts with calmodulin (CAM) and the cell death suppression activities of AtBI-1 in plant cells are mediated by modulation of ion homeostasis. In addition, Oshimo et al. [49] reported that $\mathrm{BI}-1$ requires a functional electron transport chain for cell death suppression in yeast [49].

Although these reports indicate that $\mathrm{BI}-1$ regulates cell death mechanism in animals, yeast, plants, the molecular mechanism by which AtBI- 1 inhibits cell death is still unclear. The cell-death induced by plant toxins that inhibit protein synthesis is also not well understood. Their mode of action on cell death needs to be studied further.
Here, we examined the ability of PAP to induce cell death in yeast cells. Yeast expressing PAP displayed apoptosis-like features such as nuclear fragmentation and ROS production. We then studied the interaction between PAP and AtBI-1 for a possible effect of AtBI-1 on PAP induced cell death in yeast. Our results showed that AtBI-1 inhibited cell death induced by PAP in yeast. PAP was able to depurinate the ribosomes and inhibit translation in the presence of AtBI-1. To our knowledge, this is the first report demonstrating that PAP induces cell death in yeast and AtBI-1 inhibits PAP-mediated cell death independent of ribosome depurination and translation inhibition.

\section{RESULTS}

PAP expression in yeast causes cell death and AtBI-1 expression attenuates PAP induced cell death

RIPs such as ricin and abrin are able to induce apoptosis in a wide variety of cells and cell lines [21]. Though many studies have been reported on toxin-induced apoptosis, we have very little knowledge of the mechanism of RIPinduced apoptosis. Because of the extreme toxicity of PAP, a type I RIP, in plant cells, the yeast, S. cerevisiae, has been used and demonstrated to be a powerful tool for genetic and biochemical characterization of PAP [50]. When PAP cDNA was expressed in yeast under the control ofGAL1 promoter, cell growth was inhibited [50]. Previous results indicated that ribosome depurination activity of PAP does not always correlate with its translation inhibition activity and is not sufficient for cytotoxicity [51]. In this study, we investigated the ability of PAP to induce cell death in yeast. PAP CDNA was transformed into yeast. Cells were grown in glucose containing medium, then switched to fresh medium containing galactose to induce expression. At different times after induction, cells were recovered from liquid medium by centrifugation and cell viability was determined on the basis of the ability to take up Evans blue dye. Fig. 1A presents results from a representative experiment, showing an increase in the number of cells taking up Evans blue dye in cultures of PAP transformants in galactose containing medium in a time dependent manner. By $24 \mathrm{~h}$ postinduction, very few cells survive. These results were confirmed using control cells harboring an empty plasmid which remained mostly dye negative indicating more viable cells (Fig. 1A).

Arabidopsis Bax Inhibitor-1 (AtBI-1), a plant antiapoptotic protein is able to suppress Bax mediated cell death in plants, as well as in yeast cells $[52,41]$. To determine if AtBI-1 affects PAP-induced cell death, we cloned full length AtBI-1 cDNA upstream of the V5 tag in pYES 2.1 (Topo Cloning Kit, Invitrogen) vector, in which the expression is under the control of yeast GAL1 promoter. W303 yeast strain has been co-transformed with shuttle vectors harboring PAP and AtBI-1 cDNAs, grown in glucose containing medium, switched to galactose containing medium for induction before staining with Evans blue. As shown in Fig. $1 \mathrm{~A}$, yeast cells expressing PAP were stained with Evans blue dye, in contrast to cells expressing AtBI-1, which remained mostly dye negative. Yeast co-expressing AtBI-1 


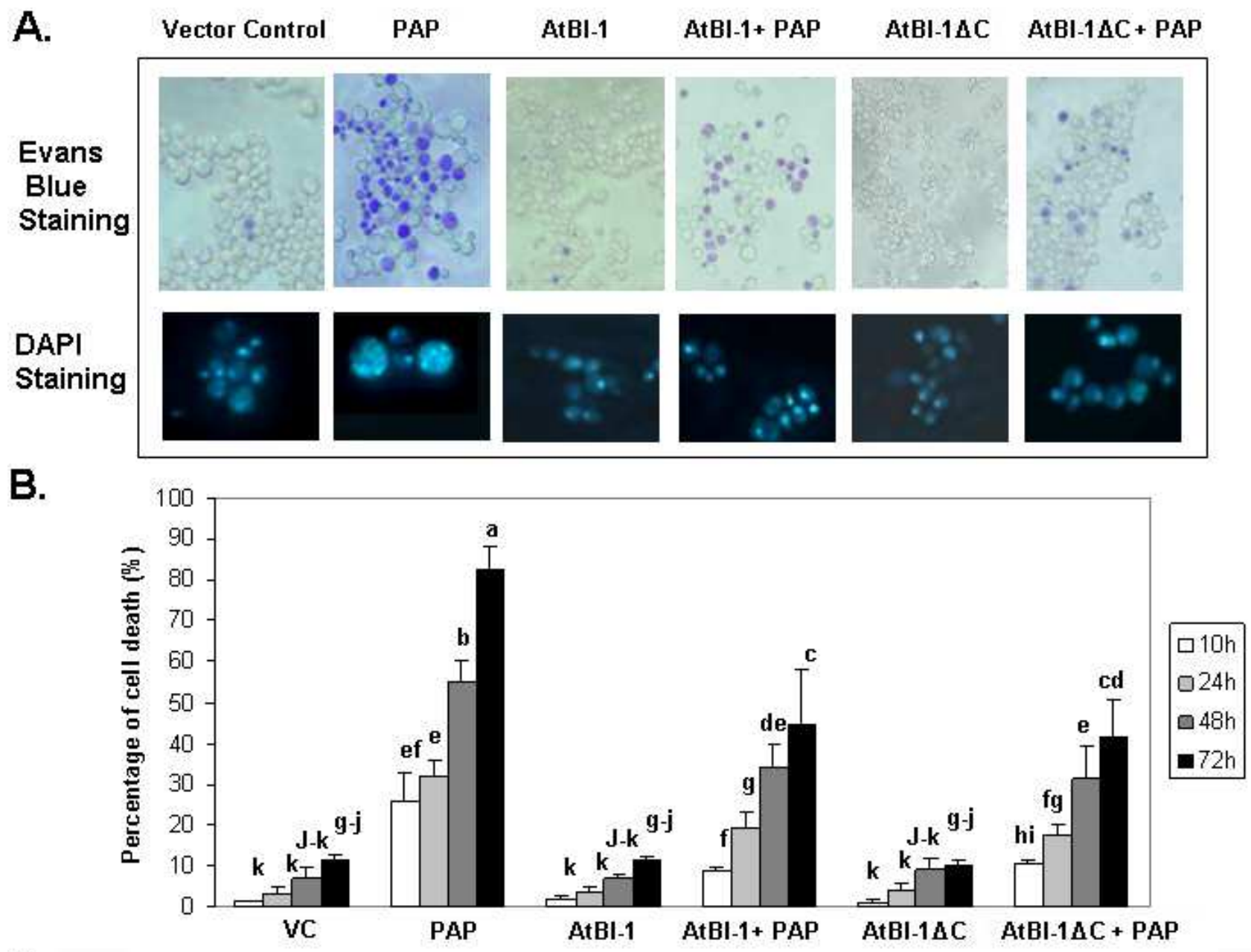

C.

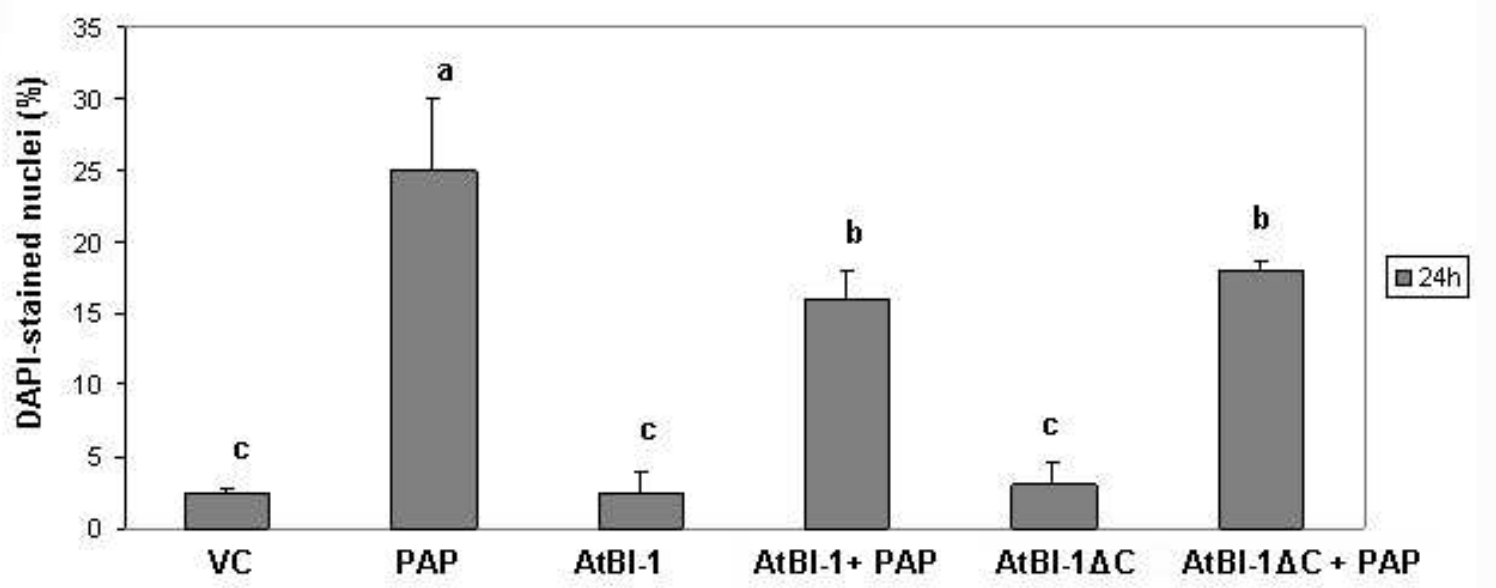

FIGURE 1: Analysis of cell death and nuclear fragmentation in yeast cells expressing PAP, AtBI-1 and AtBI-1 $\Delta$ C. (A) Cells were stained with Evans Blue or DAPI at $24 \mathrm{~h}$ after induction and visualised using Zeiss Axiovert 200 inverted microscope (magnification, X 40) nuclei are shown enlarged 40 times relative to the yeast cells. (B) The percentage of the cell death at different hours after induction were quantified and are represented as the means \pm standard deviation $(n=3)$. (C) DAPI stained nuclei at $24 \mathrm{~h}$ post-induction were quantified and are represented as the means \pm standard deviation $(n=3)$. At least 100 cells were counted per experiment. The results represent three independent experiments. VC - vector control. Columns are statistically different according to ANOVA $(P<0.001)$ followed by a post-hoc Fisher's Least Significant Difference (LSD) test. 
and PAP showed more Evans blue dye excluding cells, indicating an increase in cell viability (Fig. 1A).

Previous studies demonstrated that the $\mathrm{C}$-terminal region of AtBI-1 is necessary for the inhibition of Bax induced cell death in yeast $[43,42]$. The deletion of the last 14 amino acids completely abolished cell death suppression ability of AtBI-1 [43]. To determine the functional domain of AtBI-1 responsible for reduced cytotoxicity of PAP, we produced AtBI-1 C-terminal truncation mutant called AtBI-1 $\Delta C$ (last 23 aa - 224 to 247 - were deleted) and subcloned it into pYES 2.1 vector upstream of V5 epitope. We next cotransformed W303 yeast strain with AtBI- $1 \Delta C$ and PAP containing plasmids, grew in glucose containing medium then switched to galactose medium for induction. Cells were stained with Evans blue to test the possible effect of C-terminal deletion of AtBI-1 on cell viability in the presence of PAP. As shown in Fig. 1A, viability of cells expressing PAP and AtBI-1 was similar to cells expressing PAP and AtBI- $1 \triangle C$, suggesting that the deletion of $C$-terminal region did not affect the ability of AtBI-1 to suppress the cytotoxicity of PAP.

Apoptotic cell death is characterized by chromatin condensation, nuclear fragmentation and DNA fragmentation in mammalian and yeast cells [53-55]. We examined nuclear fragmentation in those cells to further characterize cell death process induced by PAP. Staining PAP expressing yeast cells with DAPI revealed nuclear fragmentation $24 \mathrm{~h}$ after induction, whereas PAP and AtBI-1 co-transformed yeast cells showed a significant decrease in the number of cells with nuclear fragmentation (Fig. $1 \mathrm{~A}$ and $1 \mathrm{C}$ ). Chromatin condensation and nuclear fragmentation had been already observed in yeast $[56,57]$. After overexpression of PAP, cells showed accumulation of DAPI staining within the area of the nucleus to the appearance of multiple stained regions within a single cell. No nuclear fragmentation was observed in cells expressing AtBI-1 or vector control. These data further confirmed that PAP induces cell death in yeast and AtBI-1 expression attenuates PAP induced cell death. In addition the mutation at C-terminal domain of AtBI-1 does not affect the death suppression ability of AtBI-1 when expressed with PAP.

\section{PAP induces ROS production in yeast}

The accumulation of ROS is one of apoptotic cell death features involved in many forms of cell death [58]in animals, yeast and plants $[55,59,60]$. To determine whether ROS generation was involved in PAP induced cell death, we quantified intracellular ROS production by using DCDHF-DA oxidation as a marker to measure intracellular levels of $\mathrm{H}_{2} \mathrm{O}_{2}$. As shown in Fig. 2, $\mathrm{H}_{2} \mathrm{O}_{2}$ level was increased in cells expressing PAP up to $24 \mathrm{~h}$ post-induction, which correlated well with cell death. In contrast, we did not observe any increase in the level of $\mathrm{H}_{2} \mathrm{O}_{2}$ up to $24 \mathrm{~h}$ post-induction in cells expressing vector control. To determine whether cell death inhibitory activity of AtBI-1 was accompanied by the inhibition of ROS generation, cells expressing PAP and AtBI1 were also examined. Measurement of ROS generation did not reveal any decrease in $\mathrm{H}_{2} \mathrm{O}_{2}$ level in cells expressing $\mathrm{PAP}$ and $\mathrm{AtBI}-1$ or $\mathrm{AtBI}-1 \Delta \mathrm{C}$, indicating AtBI-1 function as a negative regulator of cell death independent of ROS accumulation, downstream of ROS or both. In addition, the Cterminal deletion of AtBI-1 did not affect $\mathrm{H}_{2} \mathrm{O}_{2}$ production in cells expressing PAP.

\section{AtBI-1 reduces PAP toxicity in yeast}

PAP expression is toxic to yeast cells. To investigate whether AtBI-1 overexpression inhibits PAP toxicity in yeast cells, we tested its ability to rescue against PAP toxicity by examining cell viability. We transformed yeast cells with AtBI-1 and PAP, then plated onto galactose selective

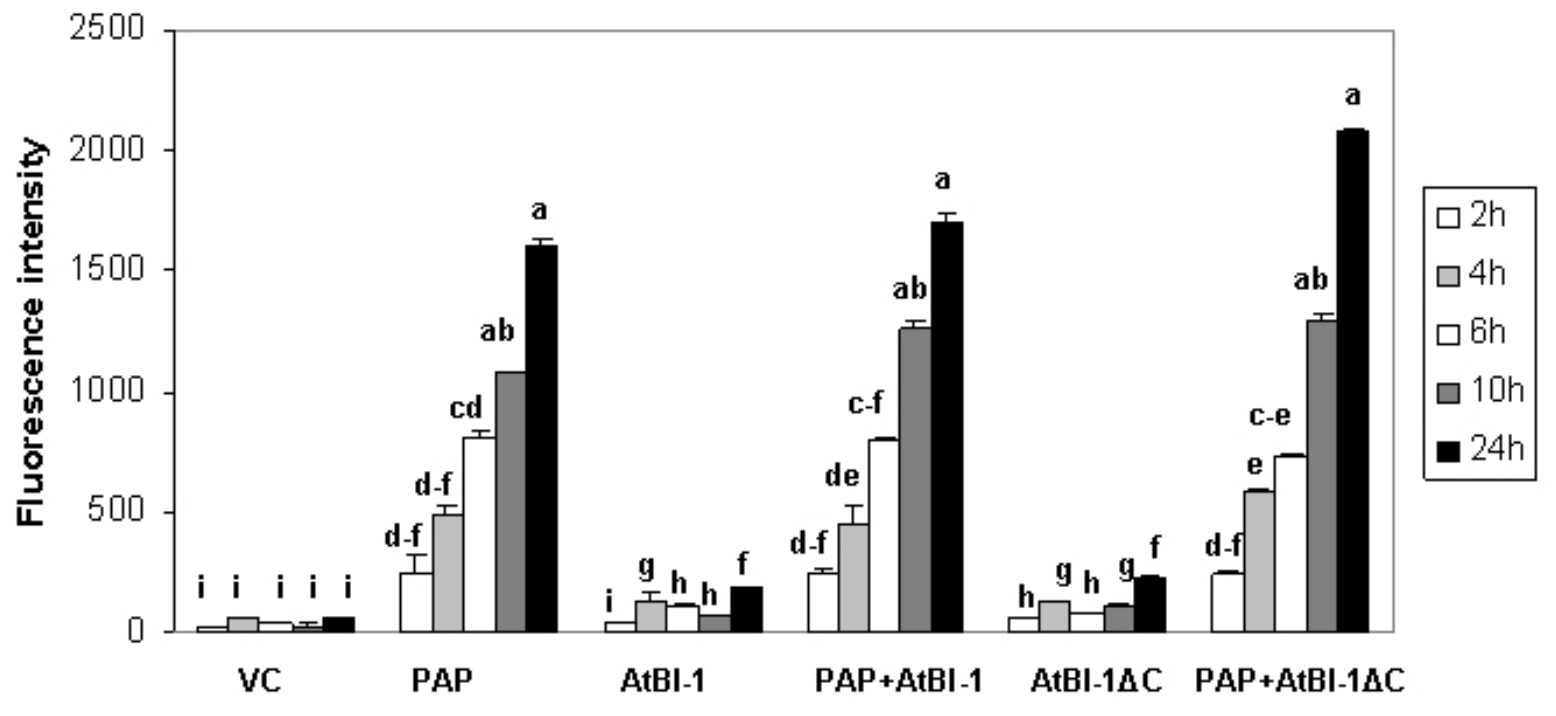

FIGURE 2: ROS generation in cells expressing PAP and AtBI-1. The amount of $\mathrm{H}_{2} \mathrm{O}_{2}$ production was quantified using DCDHF-DA. The results are represented as the means \pm standard deviation $(n=3)$. VC - vector control. The results represent three independent experiments. Columns are statistically different according to ANOVA $(P<0.001)$ followed by a post-hoc Fisher's Least Significant Difference (LSD) test. 
media to induce PAP and AtBI-1 expression. The empty plasmid has been used as a negative control. We then investigated irreversible growth inhibition by carrying out cell viability assay. Yeast cells transformed with PAP and AtBI-1 have been induced in liquid selective medium containing galactose (different induction times were tried out), then they were plated on medium containing glucose. As shown in Fig. 3, PAP expression reduced cell viability at $4 \mathrm{~h}$ post-induction, whereas yeast cells expressing PAP in the presence of AtBI-1 slightly restored growth of colonies, indicating reduction of PAP toxicity. We conclude that AtBI1 is capable of rescuing yeast cells from PAP toxicity.

Cells expressing PAP and AtBI- $1 \Delta \mathrm{C}$ restored growth of colonies at $4 \mathrm{~h}$ as compared to cells expressing only PAP. Interestingly, AtBI-1 $\triangle \mathrm{C}$ could protect yeast cells from cytotoxicity of PAP as well as the full length AtBI-1. These results indicate that $\mathrm{C}$-terminus of AtBI- 1 is not critical for reducing the cytotoxicity of PAP.

\section{PAP depurinates ribosomes in the presence of AtBI-1}

To determine if the reduction in PAP toxicity in the presence of AtBI-1 is due to reduced depurination of ribosomes, we examined ribosome depurination using a primer extension assay. After inducing PAP and AtBI-1 expression in galactose containing media in yeast, we isolated total RNA and examined depurination by using a previously described dual primer extension assay [61]. As shown in Fig. 4, ribosomes were depurinated in yeast cells expressing PAP and AtBI-1 at similar levels as in cells expressing PAP alone. Depurination in cells expressing PAP peaks by $4 \mathrm{~h}$ and de-
PAP

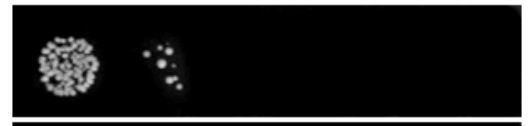

PAP+AtBI-1

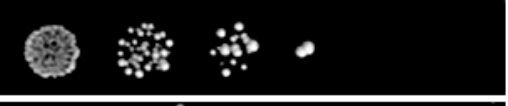

$\mathrm{PAP}+\mathrm{AtBI}-1 \Delta \mathrm{C}$

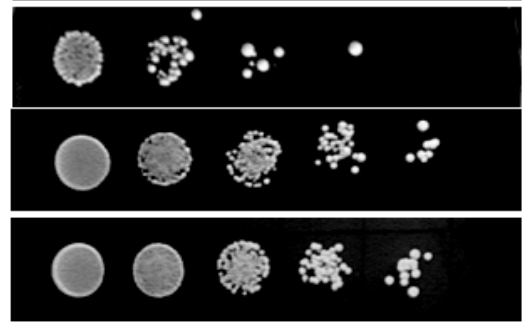

AtBl- $1 \Delta \mathrm{C}$

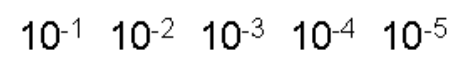

FIGURE 3: Expression and functional characterization of AtBI-1. Yeast cells containing AtBI-1 or PAP were grown in SD-U-L/raf overnight then diluted into SD-U-L/galactose for induction at $4 \mathrm{~h}$ for PAP and AtBI-1, then serial dilution were spotted on glucose containing plates and incubated for $48 \mathrm{~h}$ at $30^{\circ} \mathrm{C}$.

creases gradually up to $10 \mathrm{~h}$ post-induction. Similarly, PAP depurinated ribosomes when it was co-expressed with AtBI-1 (Fig. 4A).

As shown in Fig. 4A and $C$, depurination decreased in cells expressing PAP by $10 \mathrm{~h}$ post-induction. Ribosomes were depurinated in cells co-expressing PAP and AtBI-1. However, depurination did not decrease in these cells, possibly because these cells did not die unlike cells ex-
A.

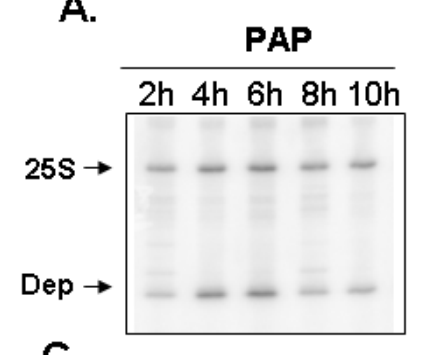

C.
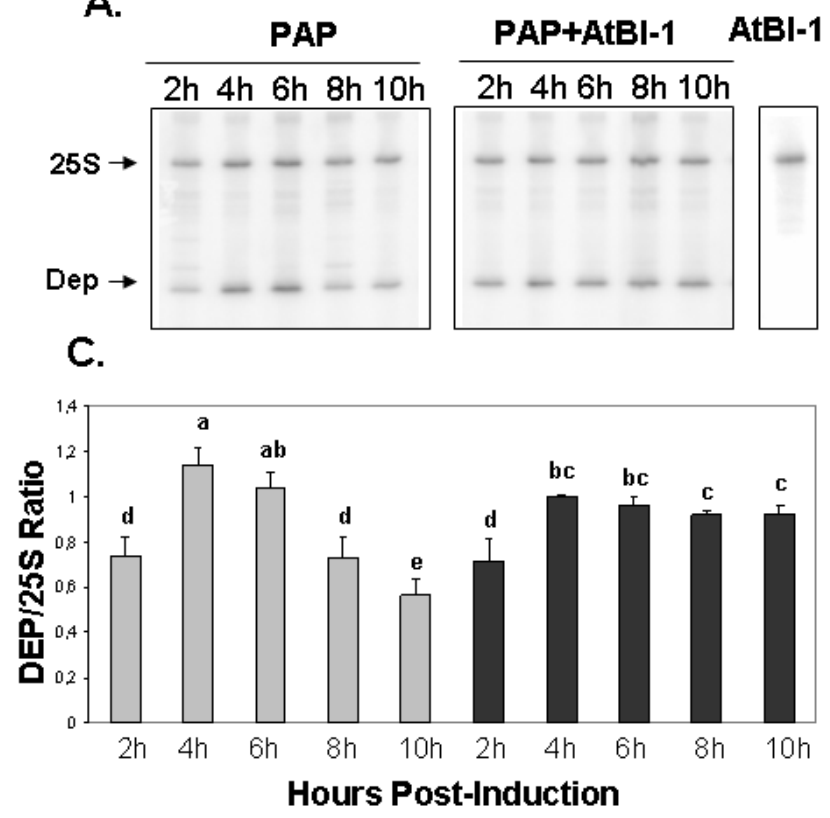

B.

D.

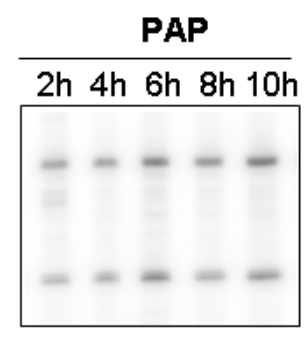

PAP+AtBI-1 $\triangle \mathrm{C}$ AtBI-1 $\triangle \mathrm{C}$
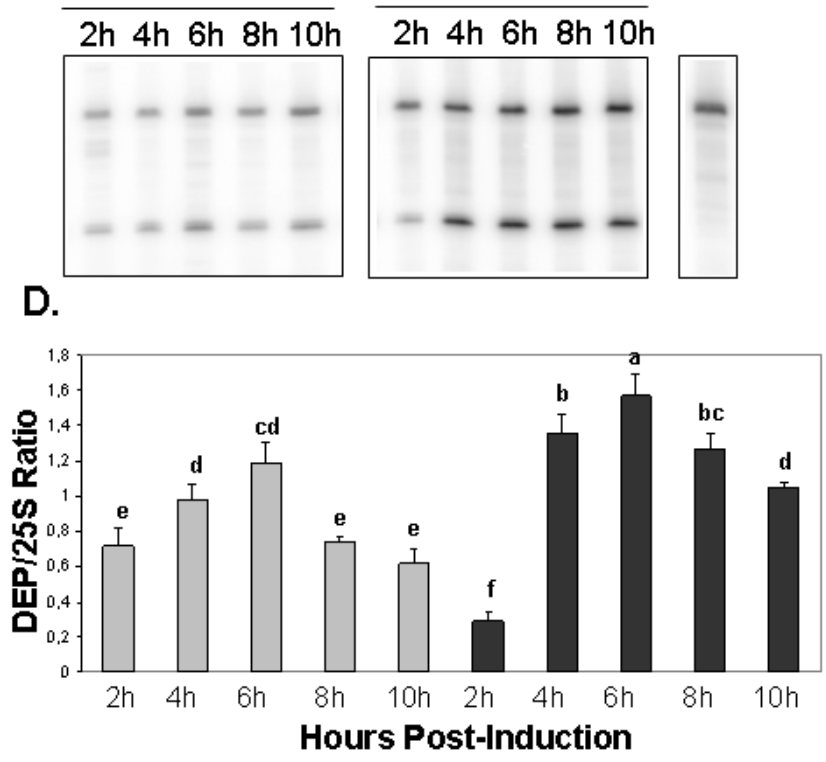

FIGURE 4: Ribosome depurination in yeast cells. Primer extension analysis in yeast cells expressing PAP and AtBI-1 (A) or PAP and AtBI$1 \triangle C(B)$ using two different end labeled primers, the depurination primer (Dep) was used to measure the extend of depurination and the 25S rRNA primer (25S) was used to measure the amount of 25S rRNA (C) and ratio of Dep/25S (D). The results represent three independent experiments. Columns are statistically different according to ANOVA $(P<0.001)$ followed by a post-hoc Fisher's Least Significant Difference (LSD) test. 
pressing PAP alone (Fig. 4 C and D). The deletion of the Cterminal domain of AtBI-1 did not reduce the ribosome depurination activity of PAP as compared to that of the full length AtBI-1 in the presence of PAP. Moreover, cells expressing PAP and AtBI-1 survive better, even though their ribosomes are depurinated.

\section{AtBI-1 does not affect translation inhibition by PAP}

To determine whether reduction of PAP toxicity is related to reduction in translation inhibition activity of PAP, we examined total translation in yeast cells expressing PAP and AtBI-1 compared with cells expressing PAP alone and vector control. Total translation was examined by $\left[{ }^{35} \mathrm{~S}\right]$ methionine incorporation at $0,4,6,10 \mathrm{~h}$ post-induction. As shown in Fig. 5A, in yeast cells expressing PAP and AtBI-1 at $4 \mathrm{~h}$ post-induction, translation was inhibited at the same level as with PAP alone, whereas in cells expressing AtBI-1, translation increased gradually over time. These results indicate that total translation is inhibited in cells coexpressing PAP and AtBI-1 at a similar level as in cells expressing $\mathrm{PAP}$ alone, indicating that $\mathrm{AtBI}-1$ expression does not have any effect on the translation inhibition activity of PAP.

\section{A.}

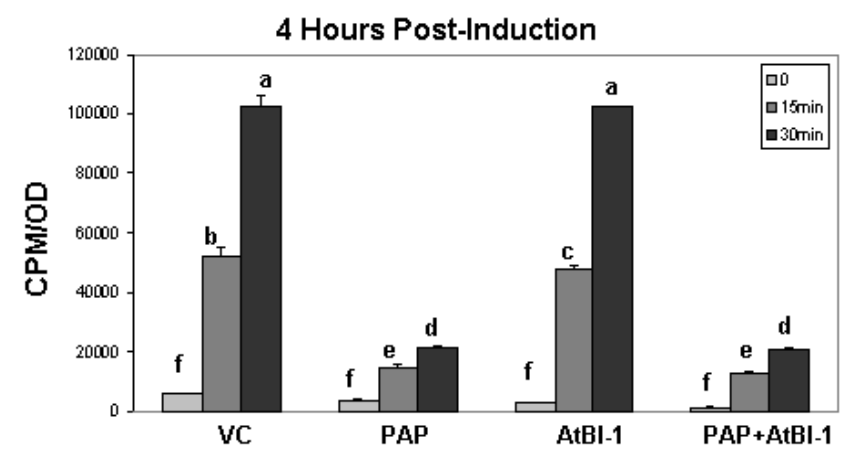

10 Hours Post-Induction

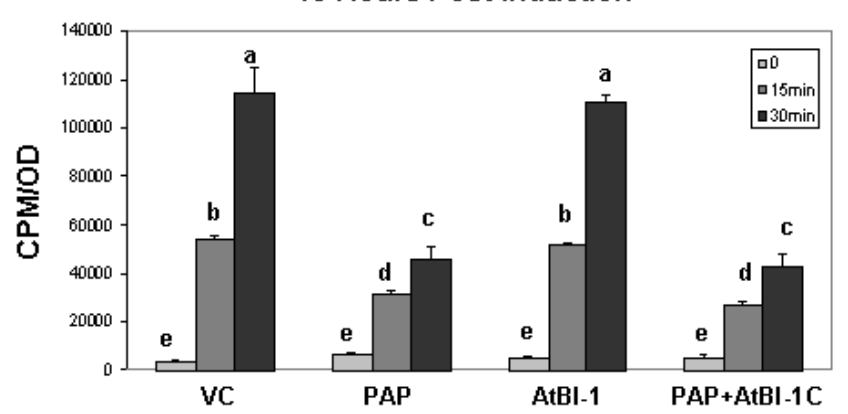

As shown in Fig. 5B, total translation was significantly inhibited in cells expressing PAP and AtBI- $1 \Delta C$ at a similar level as PAP alone, whereas total translation was not inhibited in cells expressing AtBI-1 mutant or vector control. These results indicate that the reduction in the cytotoxicity of PAP in the presence of full length or C-terminally deleted AtBI-1 is not due to a decrease in the translation inhibitory activity of PAP.

\section{AtBI-1 and PAP mRNAs are upregulated in yeast co-} expressing AtBI-1 and PAP

To determine if the reduction in the cytotoxicity of PAP is due to a decrease in PAP expression we isolated total RNA and examined PAP mRNA expression pattern in yeast cells co-expressing PAP and AtBI-1 at various times postinduction (Fig. 6). PAP mRNA level in yeast expressing AtBI1 was upregulated compared to yeast expressing PAP alone (Fig. 6A). PAP transcript level increased by 11-fold compared to that of PAP alone by $6 \mathrm{~h}$ post-induction, and then decreased up to $10 \mathrm{~h}$ post-induction. AtBI-1 mRNA level increased by 4 hours post-induction and decreased gradually up to $10 \mathrm{~h}$ post-induction in yeast expressing AtBI-1 alone, suggesting possible autoregulation. AtBI-1
B.

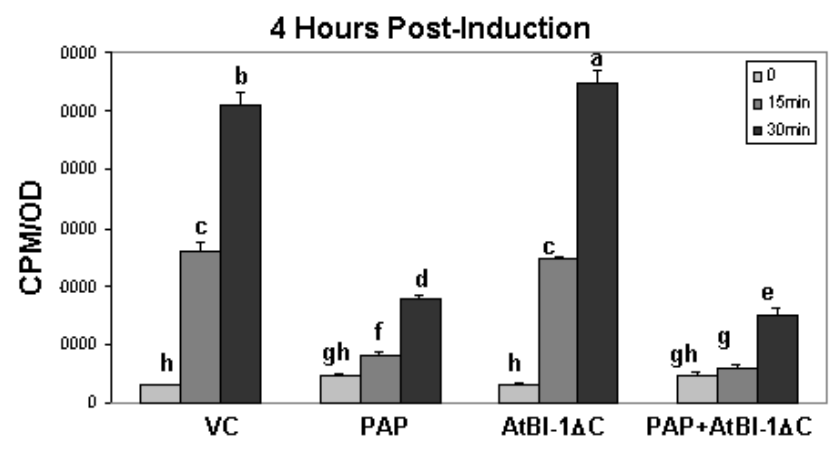

FIGURE 5: Analysis of total translation in yeast cells. (A) Total translation in yeast cells expressing PAP and AtBI-1. (B) Total translation in yeast cells expressing PAP and AtBI- $1 \Delta \mathrm{C}$. Yeast cells were grown in SD-L-U-Met and $2 \%$ glucose overnight then switched to $2 \%$ galactose containing media to induce the expression. At time $0,\left[{ }^{35} \mathrm{~S}\right]$ methionine was added to cells growing on galactose which expressed PAP or AtBI-1 and incorporation of $\left[{ }^{35} \mathrm{~S}\right]$ methionine was determined at the indicated times. Each point was repeated in duplicate. The results represent three independent experiments. VC - vector control. Columns are statistically different according to ANOVA (P < 0.001$)$ followed by a posthoc Fisher's Least Significant Difference (LSD) test. 
mRNA accumulated at a higher level at $2 \mathrm{~h}$ post-induction and stayed at a similar level up to $6 \mathrm{~h}$ post-induction in cells co-expressing PAP and either full-length or Cterminally deleted AtBI-1 (Fig. 6B). We conclude that AtBI-1 and PAP mRNA expression is upregulated in yeast cells expressing both proteins, consistent with the reduction in the cytotoxicity of PAP in these cells.

\section{AtBI-1 and PAP proteins are expressed}

We then investigated PAP expression level in yeast extracts to determine whether the reduced cytotoxicity of PAP is due to altered expression or subcellular localization. We fractionated yeast extracts at various times after induction into cytoplasmic and membrane fractions [62] and analyzed each fraction for the presence of PAP and AtBI-1 proteins. ER membrane protein, Dpm1p and the cytosolic protein Pgk1p have been used as controls for fractionation. It has been already reported that both the precursor form of PAP and the mature form are associated with the ER membrane in yeast [63]. As shown in Fig. 7A, PAP level was higher in both the membrane and the cytosol fraction at 4 and $6 \mathrm{~h}$ post-induction in yeast cells expressing PAP and AtBI-1 as compared to that of the cells expressing PAP alone. We analyzed AtBI-1 expression in both cytosolic and membrane fractions (Fig. 7B). AtBI-1 was detected in the cytosol and membrane fraction in cells expressing AtBI-1 alone. However, AtBI-1 was detected only in the membrane fraction in cells expressing AtBI-1 together with PAP (Fig. 7B). AtBI-1 and PAP mRNA expression did not correlate to protein levels in yeast cells expressing both proteins. This was previously observed by Di et al. [64].

In contrast to full-length AtBI-1, we did not observe any AtBI- $1 \Delta C$ in the cytosolic fraction (Fig. 7B). When cotransformed with AtBI- $1 \Delta C$ and PAP, yeast cells slightly expressed AtBI-1 $\triangle \mathrm{C}$ in cytosolic fraction by 24 hours postinduction (Fig. 7B).

\section{AtBI-1 binds to PAP in vitro}

To examine the possibility that AtBI-1 may reduce the cytotoxicity of PAP by binding to it and forming a heterodimer, we used a co-immunoprecipitation assay in yeast cells expressing both PAP and AtBI-1. Total protein extracted from yeast co-expressing PAP and AtBI-1 were coimmunoprecipitated with the V5 monoclonal antibody. Total protein extracted from yeast expressing PAP alone and vector control was used as a negative control. PAP and AtBI-1 were co-immunoprecipitated with V5 antibody (Fig. $8 \mathrm{~A})$. Immunoblot analysis using total lysate was used to
A.

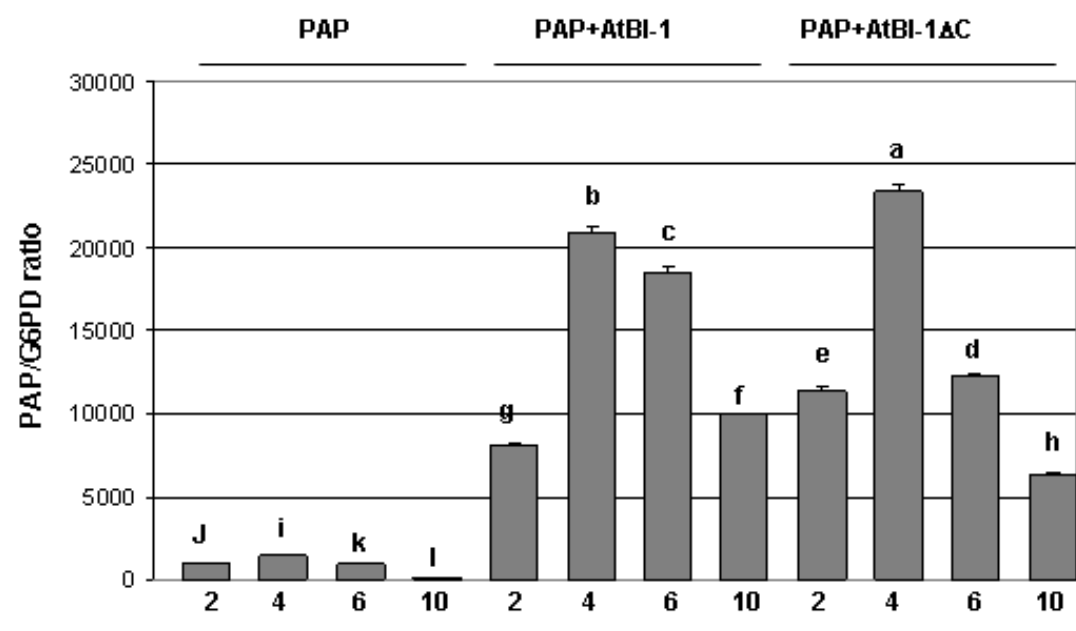

B.

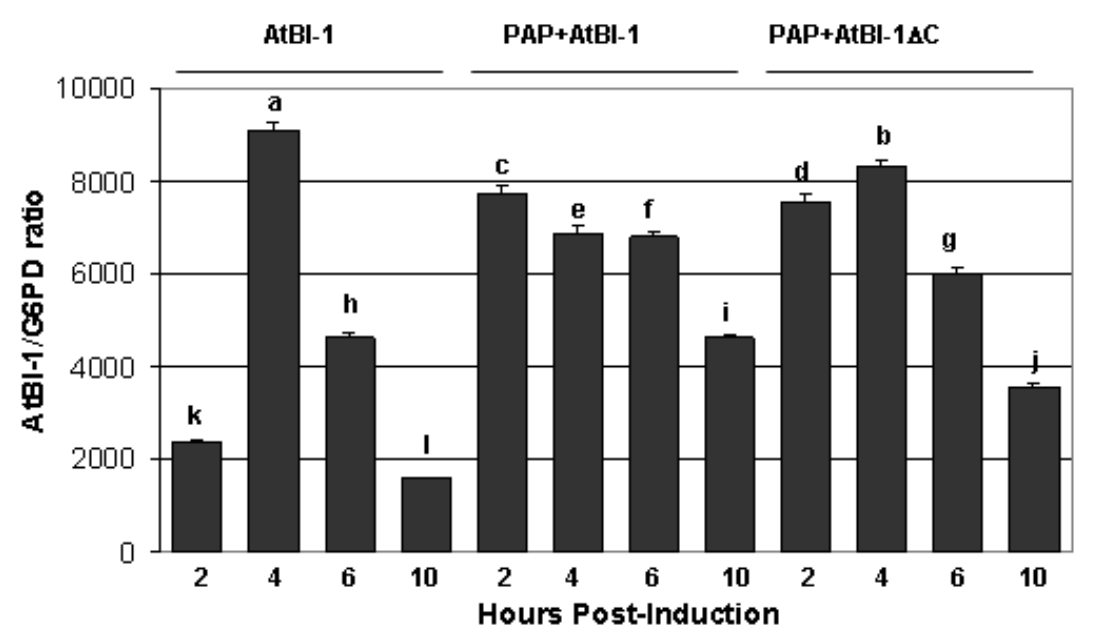

FIGURE 6: Real-time PCR analysis of mRNA levels in yeast cells. (A) Analysis of PAP mRNA in yeast cells expressing AtBI-1. (B) Analysis of AtBI-1 mRNA in yeast cells expressing PAP. Cells were grown on galactose for the hours indicated. The mRNA levels for the genes were normalized to G6PD mRNA using the $\triangle \Delta C T$ method from Applied Biosystems. The results represent three independent experiments. Columns are statistically different according to ANOVA $(P<0.001)$ followed by a post-hoc Fisher's Least Significant Difference (LSD) test. 
show the level of expression of both proteins (Fig. 8B). We next performed co-immunoprecipitation assay using AtBI$1 \triangle \mathrm{C}$. These results indicated that AtBI- 1 binds directly to PAP and C-terminal deletion of 23 aa did not change the binding capacity of AtBI-1 to PAP. These finding demonstrate that AtBI-1 can rescue yeast cells from cytotoxicity of PAP by binding it to form a heterodimer.

\section{DISCUSSION}

We present evidence here that cells expressing PAP, a type I ribosome inactivating protein, exhibit nuclear fragmentation characterized by DAPI stained multiple regions in the nucleus with extensive vacuolization. These alterations were absent in cells expressing vector control, AtBI-1 and AtBI- $1 \Delta C$ (Fig. 1). The number of cells exhibiting nuclear fragmentation was decreased in cells expressing PAP and AtBI-1, indicating protective effect of AtBI-1 on PAP induced cell death. Besides inhibition of protein synthesis, PAP, a type I RIP, cleaves single-stranded [65] as well as double-stranded DNA [17] using the same active site required to depurinate rRNA. The cleavage of DNA in the nucleus and nuclear fragmentation are typical apoptotic features in yeast $[66,67]$. It is tempting to think that the nuclear fragmentation in cell death induced by PAP is due to its nuclease activity. Similarly, some RIPs induce DNA damage by their nuclease activity $[20,68]$. However, this
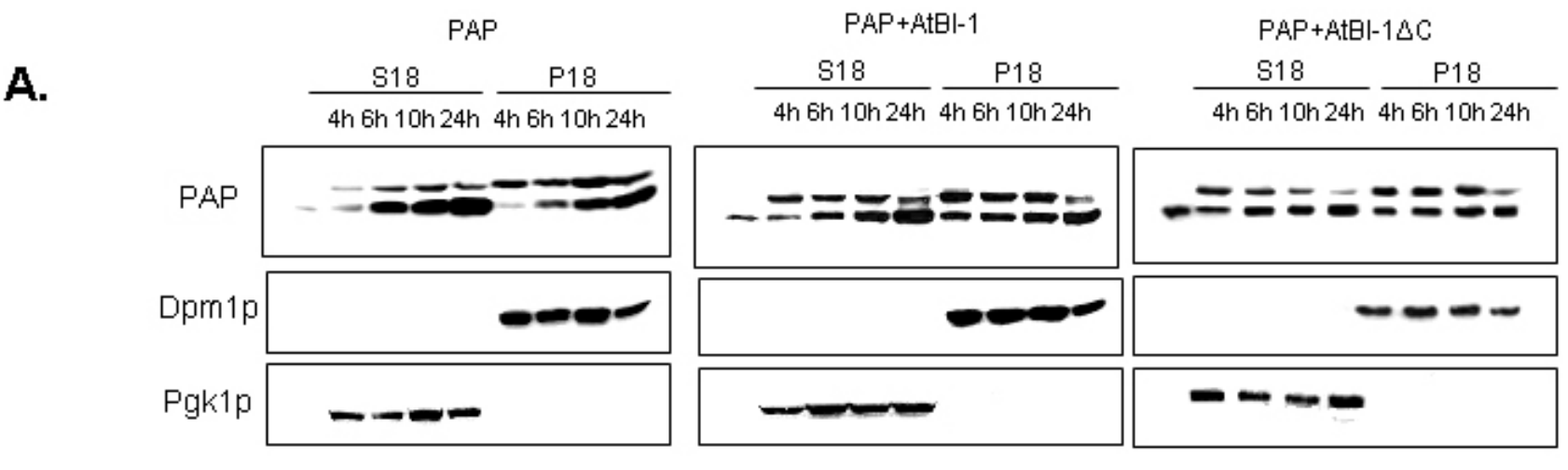

AtEl-1

PAP+AtEl-1

B.

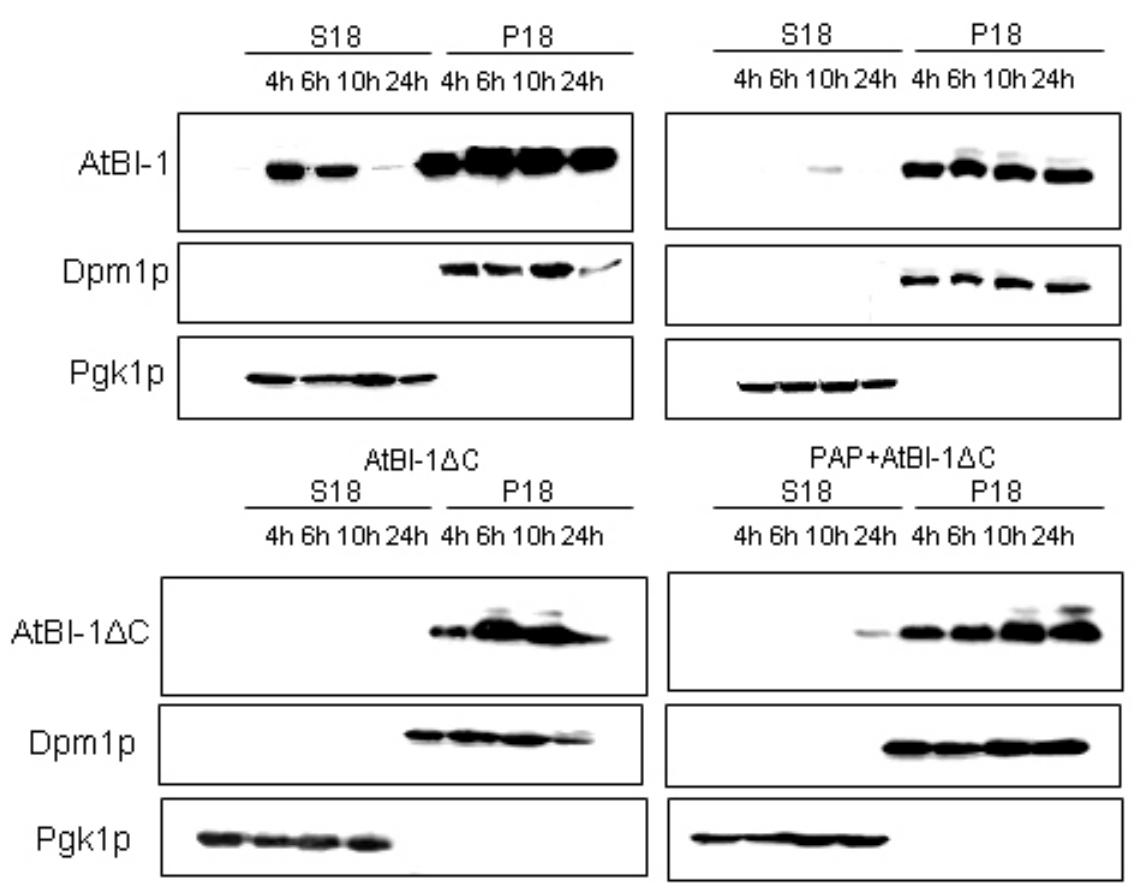

FIGURE 7: Immunoblot analysis. (A) PAP expression in yeast cells expressing AtBI-1 or AtBI-1 $\Delta C$ C. (B) AtBI-1 or AtBI-1 $1 \Delta C$ expression in yeast cells expressing PAP. Yeast transformants were grown in SD-U-L glucose media. The expression of PAP and AtBI-1 was induced for indicated hours, lysed and fractionated into membrane (P18) and cytosolic (S18) components. The amount of $10 \mathrm{mg}$ protein was separated on $15 \%$ SDS-PAGE. Proteins were transferred into nitrocellulose membrane and probed with polyclonal PAP antiserum and monoclonal V5 antibody. The membrane marker Dpm1p and the cytosolic marker Pgk1p were used as controls to show equal amount of loading and lack of crosscontamination. 
aspect needs to be studied in depth to determine whether RIPs can enter the nucleus to induce DNA damage by nuclease activity and trigger apoptosis.

ROS production is involved in many types of cell death processes in animals, yeast and plants $[55,59,60]$. Previous studies showed that ROS production is implicated in ricin-induced apoptotic cell death in mammalian cells as well as in yeast $[28,69]$. Yeast cells exposed to oxidative stress or expressing mammalian Bax also induce ROS production [57]. To determine if ROS is accumulated in yeast expressing PAP, intracellular ROS levels were quantified. The ROS accumulation in cells expressing PAP at 24 hours post-induction was almost 2-fold higher than that of vector control suggesting that ROS may act as an effector of apoptosis and trigger cell death signaling pathways. ROS induction precedes cell death in PAP expressing cells, suggesting that ROS may act as an effector of apoptosis and trigger cell death signaling pathways in those cells. In this study, we demonstrated for the first time that PAP, a type I RIP induces ROS production. Since ribosome depurination and translation inhibition are not always correlated with the cytotoxicity of PAP, ROS production in cells expressing PAP may be an important step, leading to PAP induced cell death.

We present the first evidence that the cytotoxicity of PAP is not only due to the depurination and translation inhibition but also to cell death in yeast.

AtBI-1 suppresses Bax induced cell death in plants, mammalian and yeast cells $[41,44,70]$. Bax induced cell death in Arabidopsis protoplast system is inhibited by the overexpression of AtBI-1 through ROS independent processes [44]. We investigated the possibility that AtBI-1 can inhibit PAP toxicity through ROS dependent processes. We did not observe any decrease in ROS production in cells expressing PAP and AtBI-1 or AtBI- $1 \Delta \mathrm{C}$, indicating that At$\mathrm{BI}-1$ functions as a negative regulator of PAP induced cell death independent of ROS accumulation or downstream of ROS, or both. In addition, the deletion of C-terminal region of AtBI-1 did not affect ROS accumulation in cells expressing both proteins suggesting that both proteins inhibit PAP toxicity via ROS independent pathway. These results correlated well with the cell viability assay. Yeast expressing PAP and AtBI-1 were able to grow on glucose containing medium after induction for $4 \mathrm{~h}$ in galactose containing media (Fig. 3). To determine the role of the C-terminal region of AtBI-1 in reduced cytotoxicity of PAP, we co-transformed yeast cells with PAP and AtBI- $1 \Delta C$, and AtBI- $1 \Delta C$ was able to rescue yeast cells from cytotoxicity of PAP at the same level as AtBI-1. It was recently reported that the deletion of C-terminal region of AtBI-1 abolishes the ability of AtBI-1 to suppress Bax-induced cell death in yeast [43]. The same authors demonstrated that the formation of coiled-coil structure in C terminus of AtBI-1 is essential for Baxinduced cell death inhibition in yeast. In our study, the deletion of 23 aa, which eliminated the predicted formation of coiled-coil structure, altered the level of AtBI-1 in the cytosol. The deletion of 23 aa at C-terminal region of AtBI-1 did not affect cell death suppression activity of AtBI1 against PAP. Our results suggest that the C-terminal region of AtBI-1 may be critical for its transport to the cytosol. Since both AtBI-1 and AtBI- $1 \Delta \mathrm{C}$ are associated with the $E R$, they may inhibit PAP associated with the ER membrane fraction in yeast. We conclude that the $\mathrm{C}$-terminal region of AtBI-1 is not critical for the interaction between AtBI-1 and PAP, and the cell death inhibition activity of AtBI-1 against PAP. The structural model of Human Bax inhibitor-1

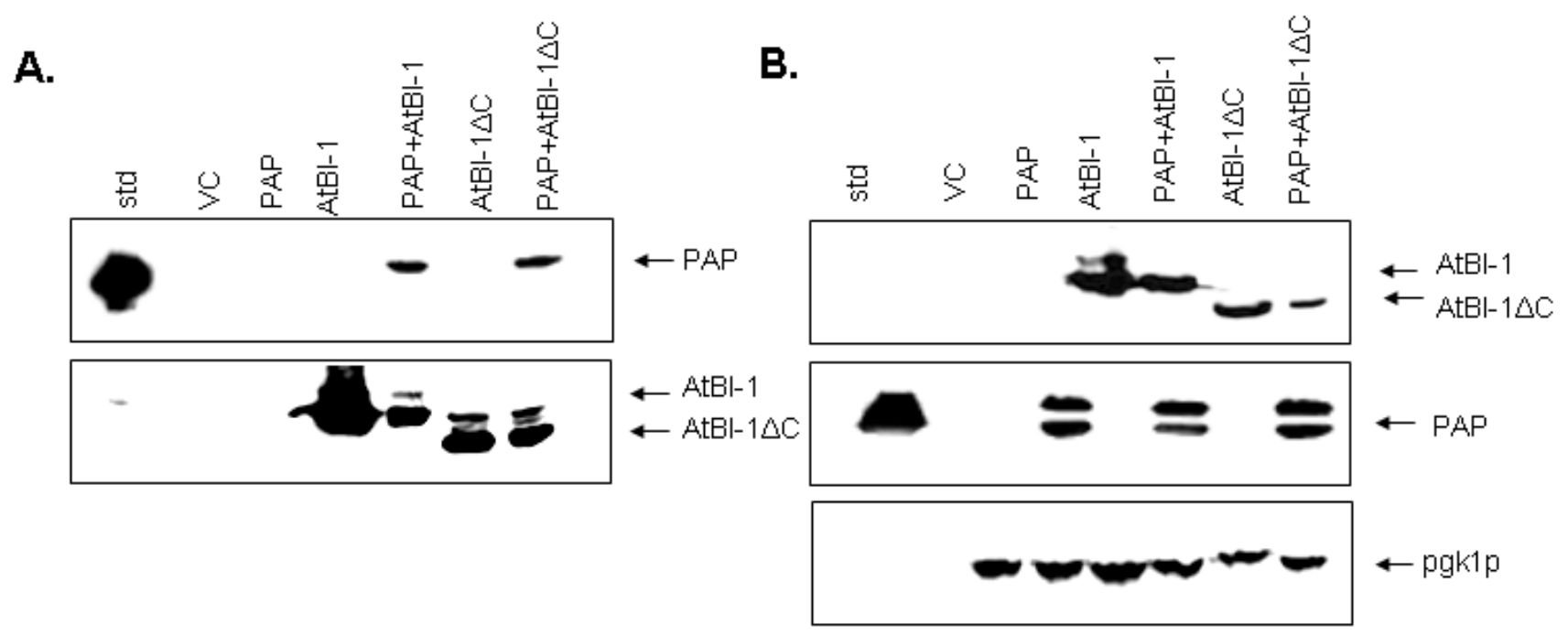

FIGURE 8: Co-immunoprecipitation assay. (A) Co-immunoprecipitation of PAP with either AtBI-1 or AtBI- $1 \Delta C$. Total proteins isolated from yeast cells induced to express PAP, AtBI-1, AtBI- $1 \Delta$ C and vector control (VC) for 6 hours were incubated with V5-antibody and immunoprecipitated with protein A-Sepharose beads. Immunoprecipitated proteins were separated on $15 \%$ SDS-PAGE, transferred to nitrocellulose and probed with affinity purified PAP antibody or with V5-antibody. (B) The total lysate from cells expressing PAP, AtBI-1 and AtBI-1 $\triangle C$ subjected to SDS PAGE/immunoblot analysis using V5 and PAP-antibody to show the level of expression of both proteins. 
(hBI-1) revealed a 6-TM topology with both $\mathrm{N}$ - and $\mathrm{C}$ termini in the cytoplasm and exhibits $\mathrm{PH}$-sensitive calcium leak activities, proposed to be mediated by the C-terminal region [71]. By homology, the C-terminal region of AtBI-1 may also have $\mathrm{PH}$-sensitive calcium leak activity.

Hudak et al. [51] identified the PAP residues that are critical for ribosome depurination, inhibition of translation and cytotoxicity, and demonstrated that ribosome depurination is not sufficient for the inhibition of translation and cytotoxicity. Our results support this observation. Even though, rRNA depurination level was higher and translation inhibition was not affected in yeast expressing PAP and either AtBI-1 or AtBI- $1 \Delta \mathrm{C}$, cells were able to survive on galactose containing medium. These results show that AtBI-1 inhibited cell death caused by PAP in yeast independent of ribosome depurination and translation inhibition.

$\mathrm{BI}-1$ was shown to be $\mathrm{Bcl}-2$ binding but not Bax-binding protein with antiapoptotic activity [70]. To further investigate a direct interaction between PAP and AtBI-1, we conducted co-immunoprecipitation assay with cells expressing both proteins. AtBI-1 as well as AtBI- $1 \Delta C$ proteins were able to bind to PAP at 6 hours post-induction. At 6 hours post-induction, both $\mathrm{AtBI}-1$ and $\mathrm{AtBI}-1 \Delta \mathrm{C}$ were able to bind to the precursor form of PAP but not to mature PAP. The deletion of 23 aa at C-terminal region of AtBI-1 did neither abolish nor diminish the binding capacity of protein to PAP suggesting that the $\mathrm{C}$-terminal region is not critical for this interaction.

Plant and animal $\mathrm{Bl}-1$ proteins are located mostly in the $E R$ and the perinuclear region $[38,41,70]$. Although the precursor form of PAP is mostly associated with the ER membrane, it is not exclusively localized in the ER [72]. At 6 $h$ post-induction we found the precursor form of PAP in cytosolic fraction as well as in the membrane fraction as described previously by Parikh et al. [72]. However, AtBI-1 was only associated with the membrane fraction in yeast co-expressing PAP and AtBI-1, suggesting that the binding may take place in the ER.

Ricin inhibits adaptation responses to ER stress by preventing HAC1 mRNA splicing and Ire1p signaling to downstream mediators of UPR [73]. The inability to activate UPR in response to ER stress contributes to ricin-mediated cell death. By analogy with ricin, we can speculate that PAP may interfere with UPR therefore causing ER stress induced cell death. We recently showed that Bax expression induced the UPR in yeast and this was associated with HAC1 mRNA splicing [74]. Yeast cells deficient for yeast bax inhibitor ( $\triangle b x i 1)$ are not only more sensitive to ER stressinducing drugs but also have a decreased UPR [75]. By homology with BXI1, AtBI-1 could also regulate PAP-induced cell death by UPR.

In summary, we show here that PAP induces cell death in yeast and AtBI-1 inhibits PAP induced cell death. We present evidence that the $\mathrm{C}$-terminal region of AtBI- 1 is not required to reduce PAP cytotoxicity. We demonstrate that AtBI-1 inhibits cell death induced by PAP independent of ribosome depurination and translation inhibition. Future experiments will characterize the mechanism by which AtBI-1 inhibits PAP cytotoxicity.

\section{MATERIALS AND METHODS}

Determination of cell viability by Evan`s blue staining, chromatin staining and ROS measurement

Cells were collected after induction at the times indicated, washed in PBS buffer and Evans blue was added to $1 \mathrm{ml}$ of 0.6 OD cells at the concentration of $0.5 \%$ in PBS buffer and stained at room temperature for $30 \mathrm{~min}$. After staining cells were washed several times with $\mathrm{ddH}_{2} \mathrm{O}$ to remove unbound dye from cultures before observation. Cells were counted using Zeis Axiovert 200 inverted microscope. The percentage of cell death was calculated by counting $~ 800$ total cells as described by Xu et al. [71].

To detect nuclear fragmentation, yeast cells were washed with PBS buffer, fixed in $100 \%$ ethanol at room temperature for $5 \mathrm{~min}$. and washed again. For nuclear staining, samples were incubated for $5 \mathrm{~min}$. with $0.5 \mathrm{\mu g}^{*} \mathrm{ml}^{-1}$ diaminopheylindole (DAP) in PBS and analyzed after washing by Zeiss Axiovert 200 inverted microscope with the epifluorescence setting (Axiovision 3.0; Carl Zeiss Vision $\mathrm{GmbH}$ ).

Intracellular production of $\mathrm{H}_{2} \mathrm{O}_{2}$ was measured using the antioxidant sensitive probe $2^{\prime}, 7^{\prime}$-dichlorodihydrofluorescein diacetate (DCDHF-DA) (Invitrogen, Carlsbad, CA). $2 \mu \mathrm{l}$ of fresh $5 \mathrm{mM}$ DCDHF-DA was added to $1 \mathrm{ml}$ of yeast culture $\left(10^{7}\right.$ cells $)$ and incubated at $28^{\circ} \mathrm{C}$ for $45 \mathrm{~min}$. The cells were then washed twice in sterile distilled water and resuspended in $1 \mathrm{ml}$ of 50 $\mathrm{mM}$ Tris- $\mathrm{HCl}, \mathrm{pH}$ 7.5. After $20 \mu \mathrm{l}$ of chloroform and $10 \mu \mathrm{l}$ of $0.1 \%$ SDS were added, the cells were incubated for $15 \mathrm{~min}$. and pelleted. The fluorescence of the supernatant was measured using an HTS700 Perkin Elmer bioassay reader (Wellesley, MA) with excitation at $485 \mathrm{~nm}$ and emission at $525 \mathrm{~nm}$.

\section{Plasmids}

The cloning of PAP CDNA into NT198 under the control of GAL1 promoter used in this study was described previously [7, 73] . AtBI-1 (AB025927) was cloned into the yeast expression vector pYES2.1 (pYES2.1 TOPO TA expression kit, Invitrogen, USA) in upstream of V5 epitope by PCR using 5'GGATCCACGATGGATGCGTTCTCTTCCTTC3' and 5'GTTTCTCCTTTTCTTCTTCTTCTC3' primers and into the PTKB175 without a tag. After the cloning, vectors were transformed into $E$. coli $\mathrm{DH} 5 \alpha$. The sequences were confirmed by sequencing two times using specific primers.

\section{Yeast transformation and cell viability}

The S. cerevisiae strain W303 (MATa ade2 trp-1 ura-3 leu23,112 his3-11,15 can1-100) (from B. Thomas, Columbia university, New York, NY) was used for all transformations.

Cells were transformed and co-transformed as described previously [51]. One-half of transformed yeast suspension was plated onto $2 \%$ glucose media, the other half was plated onto $2 \%$ galactose containing media. The toxicity of PAP was verified by re-plating the selected colonies onto both $2 \%$ glucose and $2 \%$ galactose media.

For cell viability, transformed and co-transformed yeast cells were grown on SD-Leu containing $2 \%$ glucose to an $A_{600}$ of 0.3 and then transferred to selective medium containing $2 \%$ galactose to induce PAP and AtBI-1 expression. A serial dilution of cells was plated on selective media containing $2 \%$ glucose at $0,4,6,10$, and $12 \mathrm{~h}$ post-induction. Plates were incubated at $30^{\circ} \mathrm{C}$ for approximately $48 \mathrm{~h}$. 


\section{Growth conditions}

Yeast cells were grown in YPD rich medium or synthetic dropout (SD) medium with appropriate amino acids at $30^{\circ} \mathrm{C}$. Yeast cells transformed with PAP and AtBI- 1 were grown initially at $30^{\circ} \mathrm{C}$ in a total volume of $100 \mathrm{ml}$ of selective medium supplemented with $2 \%$ raffinose to a starting $A_{600}$ of 0.6 . Yeast cells were pelleted by centrifugation and washed with SD medium before replacing with $100 \mathrm{ml}$ of selective medium containing $2 \%$ galactose to a starting $A_{600}$ of 0.3 . Then, $5 \mathrm{ml}$ of culture were sampled for protein isolation, $10 \mathrm{ml}$ of culture for RNA isolation and $1 \mathrm{ml}$ for a growth reading $\left(A_{600}\right)$ at different times post-induction.

\section{Yeast protein expression analysis}

Total protein extraction from frozen yeast cells collected at different times post-induction was extracted as described by Hudak et al. [76]. Samples were separated on 15\% SDS-PAGE, transferred to nitrocellulose membrane (Roche) and probed with affinity purified anti-PAP polyclonal antibody (1:5000). The AtBI-1 and mutant forms of AtBI-1 proteins level were determined by using V5 monoclonal antibody (1:5000) that recognize V5 epitope at C-terminal of the protein. PAP, AtBI-1 and AtBI-1 mutants were visualized by chemiluminescence using the Renaissance kit (PerkinElmer Life Sciences). The blots were then stripped with $8 \mathrm{M}$ guanidine hydrochloride for $30 \mathrm{~min}$ and reprobed with 3-phosphoglycerate kinase (Pgk1 p; Molecular probes) (1:10000) as an internal loading control.

For cell fractionations, protein from frozen yeast cells collected during various times post-induction was extracted as described by Frey et al. (2001). Briefly, after addition of lowsalt (LS) buffer (20mM HEPES-KOH, pH 7.6, $100 \mathrm{mM}$ potassium acetate, $5 \mathrm{mM}$ magnesium acetate, $1 \mathrm{mM}$ EDTA, 2mM DTT and $0.1 \mathrm{mM}$ PMSF, yeast protease inhibitor cocktail (Sigma) and acid-washed glass beads (Sigma), cells were vortexed for 1 min and chilled for $1 \mathrm{~min}$ on ice for a total of 8 cycles. Crude lysates were spanned at $1200 \mathrm{~g}$ for $2 \mathrm{~min}$. The same lysate was then centrifuged an additional $20 \mathrm{~min}$ at $18000 \mathrm{~g}$. The pellet was washed twice with ice cold water and resuspended in LS buffer. The supernatant and pellet fraction were stored at $80^{\circ} \mathrm{C}$.

\section{RNA analysis}

Total RNA was extracted from yeast using hot phenol [17]. cDNA was synthesized from $1 \mu \mathrm{g}$ of total RNA in a $20 \mu \mathrm{l}$ reaction, containing $1 \times$ first-strand buffer (Invitrogen), $40 \mathrm{U} / \mu \mathrm{l}$ RNA Guard RNase inhibitor (Promega, Madison, WI, USA), 0.5 $\mu \mathrm{g}$ poly $\mathrm{d}(\mathrm{T})$ oligonucleotide (Promega), $40 \mathrm{mM}$ dNTPs and Superscript II (Invitrogen) reverse transcriptase. Quantification of transcript levels by real-time PCR analysis was performed using an ABI Prism 7000 Sequence Detection System using the manufacturers' protocols. For quantitative $\mathrm{PCR}$, the primers used were as follows:

PAP, 5'-gggtaagatttcaacagcaattca-3' and 5'-caccactggcatccactagct-3';

G6PD 5'-CAGCAATGACTTTCAACATC-GAA-3' and 5'-CCGGCACGCATCATGAT-3';

AtBI-1, 5'-GTTGTGCTCTTGTGGCGTCTGC-3' and 5' - TCAAGGGGCCAACAGAAGCACCT-3'.

\section{In vivo $\left[{ }^{35} \mathrm{~S}\right]$ Methionine Incorporation}

Yeast cells were grown to an $A_{600}$ of 0.6 in SD selective medium supplemented with $2 \%$ raffinose. Cells were then resus- pended at an $A_{600}$ of 0.3 in $2 \%$ galactose containing SD selective medium for 4-10 hours in order to induce either PAP, AtBI-1 or mutant forms of AtBI-1. At time zero, $\left[{ }^{35} \mathrm{~S}\right]$ methionine was added to cells growing on galactose. At the various times post-induction, $600 \mathrm{ml}$ of yeast cells were taken for growth measurements and an aliquot of $800 \mathrm{ml}$ were assayed for methionine incorporation in triplicate as described by Parikh et al. 2002. Briefly, the yeast were added to $200 \mathrm{ml}$ of $100 \%$ trichloroacetic acid and incubated for $10 \mathrm{~min}$ on ice followed by $20 \mathrm{~min}$ at $70^{\circ} \mathrm{C}$. The precipitate then filtered through 24-mm glass microfiber filters (VWR), washed with ice-cold $5 \%$ trichloroacetic acid followed by $95 \%$ ethanol. Filters were dried overnight and incorporation was quantified in a scintillation counter. The $\mathrm{Cpm}$ was normalized to the $A_{600}$ reading.

\section{rRNA depurination Assay}

Depurination of ribosomal RNA was performed by primer extension analysis in according to Hudak et al.[15]. $2 \mathrm{mg}$ of total yeast RNA from transformants was incubated with $\left(\alpha-{ }^{32} P\right)$ ATP end labeled $5^{\prime}$ reverse primer ( $5^{\prime}$ - AGCGGATGGTGCTTCGCGGCAATG-3') complementary to $73 \mathrm{nt} 3^{\prime}$ end of depurination site for depurination product and $5^{\prime}$ reverse primer ( $5^{\prime}$ TTCACTCGCCGTTACTAAGG-3') specific to the $3^{\prime}$ end of yeast $25 \mathrm{~S}$ rRNA as an internal control. The presence of depurination was observed by synthesis of a $73 \mathrm{nt}$ extension product corresponding to the depurination site. An aliquot of $4 \mathrm{ml}$ of extension product was separated on a $6 \%$ polyacrylamide/7 M urea denaturing gel and visualized and quantified on a Phosphorlmager (Amersham Biosciences).

\section{Co-immunoprecipitation}

PAP and AtBI-1 expressed in vivo yeast cells were coimmunoprecipitated with the monoclonal antibody against V5 epitope essentially as described by Otto and Lee [77]. Total protein extracts from cells induced to express PAP, AtBI- 1 at 6 $h$ post-induction were used as substrate for immunoprecipitation with Protein A-Sepharose beads. Proteins were eluted from the beads with SDS sample buffer and visualized by immunoblot analysis using the antibodies to PAP and AtBI-1.

\section{Statistical analyses}

The data were subjected to ANOVA test according to completely randomized factorial design. Differences between means were determined with Fisher's Least Significant (LSD) test. $P$ value of $\leq 0.001$ was considered statistically significant. All values are presented as the mean of three independent experiments with the corresponding Standard Deviation (SD).

\section{ACKNOWLEDGMENTS}

This work was supported by National Science Foundation grants MCB-0348299 and MCB-0130531 to Nilgun E. Tumer. We are grateful to Dr. Özlem Tuncay for her help in statistical analyses.

\section{CONFLICT OF INTEREST}

The authors declare no conflict of interest. 


\section{COPYRIGHT}

(C) 2015 Çakır and Tumer. This is an open-access article released under the terms of the Creative Commons Attribution (CC BY) license, which allows the unrestricted use, distribution, and reproduction in any medium, provided the original author and source are acknowledged.

\section{REFERENCES}

1. Endo $Y$, Tsurugi $K$ (1988) The RNA N-glycosidase activity of ricin Achain. Thecharacteristics of the enzymatic activity of ricin A-chain with ribosomes and with rRNA. J Biol Chem 263: 8735-8739.

2. Endo Y, Mitsui K, Motizuki M, Tsurugi K (1987) The mechanism of action of ricin and related toxic lectins on eukaryotic ribosomes. The site and the characteristics of the modification in $28 \mathrm{~S}$ ribosomal RNA caused by the toxins. J Biol Chem 262: 5908-5912.

3. Wool IG, GI,ck A, Endo Y (1992) Ribotoxin recognition of ribosomal RNA and a proposal for the mechanism of translocation. Trends Biochem Sci 17: 266-269.

4. Barbieri L, Battelli M, Stirpe F (1993) Ribosome-inactivating proteins from plants. Biochim Biophys Acta 1154: 237-287.

5. Wang $P$, Turner NE (2000) Virus resistance mediated by ribosome inactivating proteins. Adv Virus Res: Academic Press. pp. 325-355.

6. Hartley MR, Legname G, Osborn R, Chen Z, Lord JM (1991) Singlechain ribosome inactivating proteins from plants depurinate Escherichia coli 23S ribosomal RNA. FEBS Lett 290: 65-68.

7. Hudak KA, Wang P, Tumer NE (2000) A novel mechanism for inhibition of translation by pokeweed antiviral protein: depurination of the capped RNA template. RNA 6: 369-380.

8. Montanaro L, Sperti S, Mattioli A, Testoni G, F S (1975) Inhibition by ricin of protein synthesis in vitro. Inhibition of the binding of elongation factor 2 and of adenosine diphosphate-ribosylated elongation factor 2 to ribosomes. J Biochem 146: 127-131.

9. Osborn RW, Hartley MR (1990) Dual effects of the ricin A chain on protein synthesis in rabbit reticulocyte lysate. E J Biochem 193: 401407.

10. Aron GM, Irvin JD (1980) Inhibition of herpes simplex virus multiplication by the pokeweed antiviral protein. Antimicrob Agents Chemother 17: 1032-1033.

11. Lodge JK, Kaniewski WK, Tumer NE (1993) Broad-spectrum virus resistance in transgenic plants expressing pokeweed antiviral protein. Proc Natl Acad Sci USA 90: 7089-7093.

12. Tomlinson JA, Walker VM, Flewett TH, Barclay GR (1974) The Inhibition of Infection by Cucumber Mosaic Virus and Influenza Virus by Extracts from Phytolacca americana. J Gen Virology 22: 225-232.

13. Ussery MA, Irvin JD, Hardesty B (1977) Inhibition of Poliovirus Replication by a Plant Antiviral Paptide. Ann New York Acad Sci 284: 431-440.

14. Zarling JM, Moran PA, Haffar O, Sias J, Richman DD, Spina CA, Myers DE, Kuebelbeck V, Ledbetter JA, Uckun FM (1990) Inhibition of HIV replication by pokeweed antiviral protein targeted to CD4+ cells by monoclonal antibodies. Nature 347: 92-95.

15. Hudak KA, Bauman JD, Tumer NE (2002) Pokeweed antiviral protein binds to the cap structure of eukaryotic mRNA and depurinates the mRNA downstream of the cap. RNA 8: 1148-1159.
Please cite this article as: Birsen Çakır and Nilgun E. Tumer (2015). Arabidopsis Bax Inhibitor-1 inhibits cell death induced by pokeweed antiviral protein in Saccharomyces cerevisae. Microbial Cell 2(2): 43-56. doi: 10.15698/mic2015.02.190

16. Tumer NE, Hwang D-J, Bonness M (1997) C-terminal deletion mutant of pokeweed antiviral protein inhibits viral infection but does not depurinate, host, ribosomes. Proc Natl Acad Sci USA 94: 3866-3871.

17. Wang $P$, Tumer NE (1999) Pokeweed antiviral protein cleaves double-stranded supercoiled DNA using the same active site required to depurinate rRNA. Nuc Acids Res 27: 1900-1905.

18. Huang $\mathrm{PL}$, Chen $\mathrm{HC}$, Kung HF, Huang $\mathrm{P}$, Huang $\mathrm{HI}$, Lee-Huang $\mathrm{S}$ (1992) Anti-HIV plant proteins catalyze topological changes of DNA into inactive forms. Biofactors 4(1):37-41.

19. Ling J, Liu W-y, Wang TP (1994) Cleavage of supercoiled doublestranded DNA by several ribosome-inactivating proteins in vitro. FEBS Lett 345: 143-146.

20. Roncuzzi L, Gasperi-Campani A (1996) DNA-nuclease activity of the single-chain ribosome-inactivating proteins dianthin 30, saporin 6 and gelonin. FEBS Lett 392: 16-20.

21. Narayanan S, Surolia A, Karande AA (2004) Ribosome-inactivating protein and apoptosis: abrin causes cell death via mitochondrial pathway in Jurkat cells. The Biochem j 377: 233-240.

22. Morimoto $\mathrm{H}$, Bonavida B (1992) Diphtheria toxin- and Pseudomonas A toxin-mediated apoptosis. ADP ribosylation of elongation factor2 is required for DNA fragmentation and cell lysis and synergy with tumor necrosis factor-alpha. The J Immun 149: 2089-2094.

23. Kochi SK, Collier RJ (1993) DNA Fragmentation and Cytolysis in U937 Cells Treated with Diphtheria Toxin or Other Inhibitors of Protein Synthesis. Exp Cell Res 208: 296-302.

24. Allam M, Bertrand R, Zhang-Sun G, Pappas J, Viallet J (1997) Cholera Toxin Triggers Apoptosis in Human Lung Cancer Cell Lines. Cancer Res 57: 2615-2618.

25. Brinkmann U, Mansfield E, Pastan I (1997) Effects of BCL-2 overexpression on the sensitivity of MCF-7 breast cancer cells to ricin, diphtheria and Pseudomonas toxin and immunotoxins. Apoptosis 2: 192198

26. Griffiths GD, Leek MD, Gee DJ (1987) The toxic plant proteins ricin and abrin induce apoptotic changes in mammalian lymphoid tissues and intestine. The J Pathol 151: 221-229.

27. Chang MP, Bramhall J, Graves S, Bonavida B, Wisnieski BJ (1989) Internucleosomal DNA cleavage precedes diphtheria toxin-induced cytolysis. Evidence that cell lysis is not a simple consequence of translation inhibition. J Biol Chem 264: 15261-15267.

28. Jetzt AE, Cheng JS, Tumer NE, Cohick WS (2009) Ricin A-chain requires $\mathrm{C}$-Jun $\mathrm{N}$-terminal kinase to induce apoptosis in nontransformed epithelial cells. Int J Biochem Cell Biol 41:2503-10.

29. Jetzt AE, Cheng J-S, Li X-P, Tumer NE, Cohick WS (2012) A relatively low level of ribosome depurination by mutant forms of ricin toxin $A$ chain can trigger protein synthesis inhibition, cell signaling and apoptosis in mammalian cells. Int. J. Biochem Cell Biol 44:2204-2211.

30. Li X-P, Baricevic M, Saidasan H, Tumer NE (2006) Ribosome Depurination Is Not Sufficient for Ricin-Mediated Cell Death in Saccharomyces cerevisiae. Infect Immun 75: 417-428. 
31. Komatsu N, Oda T, Muramatsu T (1998) Involvement of Both Caspase-Like Proteases and Serine Proteases in Apoptotic Cell Death Induced by Ricin, Modeccin, Diphtheria Toxin, and Pseudomonas Toxin. J Biochem 124: 1038-1044.

32. Fujii J, Matsui T, Heatherly DP, Schlegel KH, Lobo PI, Yutsudo T, Ciraolo GM, Morris RE, Obrig T (2003) Rapid Apoptosis Induced by Shiga Toxin in HeLa Cells. Infect Immun 71: 2724-2735.

33. Zhang C, Gong Y, Ma H, An C, Chen D, Chen ZL (2001) Reactive oxygen species involved in trichosanthin-induced apoptosis of human choriocarcinoma cells. The Biochem j 355: 653-661.

34. Hückelhoven R (2004) BAX Inhibitor-1, an ancient cell death suppressor in animals and plants with prokaryotic relatives. Apoptosis 9: 299-307.

35. Kawai M, Pan L, Reed JC, Uchimiya H (1999) Evolutionally conserved plant homologue of the Bax Inhibitor-1 (BI-1) gene capable of suppressing Bax-induced cell death in yeast. FEBS Lett 464: 143-147.

36. Matsumura H, Nirasawa S, Kiba A, Urasaki N, Saitoh H, Ito M, Kawai-Yamada M, Uchimiya $H$, Terauchi R (2003) Overexpression of Bax inhibitor suppresses the fungal elicitor-induced cell death in rice (Oryza sativa L.) cells. The Plant J 33: 425-434.

37. Sanchez P, De Torres Zabala M, Grant M (2000) AtBI-1, a plant homologue of Bax Inhibitor-1, suppresses Bax-induced cell death in yeast and is rapidly upregulated during wounding and pathogen challenge. The Plant J 21: 393-399.

38. Bolduc N, Brisson LF (2002) Antisense down regulation of NtBI-1 in tobacco BY-2 cells induces accelerated cell death upon carbon starvation. FEBS Lett 532: 111-114.

39. Eichmann R, Schultheiss H, Kogel K-H, Hückelhoven R (2004) The Barley Apoptosis Suppressor Homologue Bax Inhibitor-1 Compromises Nonhost Penetration Resistance of Barley to the Inappropriate Pathogen Blumeria graminis f. sp. tritici. Mol Plant-Microbe Interactions 17: 484-490.

40. Chae H-J, Kim H-R, Xu C, Bailly-Maitre B, Krajewska M, Krajewski S, Banares S, Cui J, Digicaylioglu M, Ke N, Kitada S, Monosov E, Thomas M, Kress CL, Babendure JR, Tsien RY, Lipton SA, Reed JC (2004) BI-1 Regulates an Apoptosis Pathway Linked to Endoplasmic Reticulum Stress. Mol Cell 15: 355-366.

41. Kawai-Yamada M, Jin L, Yoshinaga K, Hirata A, Uchimiya H (2001) Mammalian Bax-induced plant cell death can be down-regulated by overexpression of Arabidopsis Bax Inhibitor-1 (AtBI-1). Proc Natl Acad Sci USA 98: 12295-12300.

42. Chae H-J, Ke N, Kim H-R, Chen S, Godzik A, Dickman M, Reed JC (2003) Evolutionarily conserved cytoprotection provided by Bax Inhibitor-1 homologs from animals, plants, and yeast. Gene 323: 101-113.

43. Kawai-Yamada M, Ohori $Y$, Uchimiya $H$ (2004) Dissection of Arabidopsis Bax Inhibitor-1 Suppressing Bax-, Hydrogen Peroxide-, and Salicylic Acid-Induced Cell Death. The Plant Cell Online 16: 21-32.

44. Baek D, Nam J, koo YD, kim DH, Lee J, jeong JC, Kwak S-s, chung WS, $\lim$ CO, bahk JD, hong JC, lee SY, Kawai-yamada M, Uchimiya $H$, Yun D-j (2004) Bax-induced cell death of Arabidopsis is meditated through reactive oxygen-dependent and -independent processes. Plant Mol Biol 56: 15-27.

45. Yoshinaga K, Arimura S-i, Hirata A, Niwa Y, Yun D-J, Tsutsumi N, Uchimiya H, Kawai-Yamada M (2005) Mammalian Bax initiates plant cell death through organelle destruction. Plant Cell Rep 24: 408-417.

46. Watanabe N, Lam E (2006) Arabidopsis Bax inhibitor-1 functions as an attenuator of biotic and abiotic types of cell death. The Plant J 45: 884-894.
47. Watanabe N, Lam E (2008) BAX Inhibitor-1 Modulates Endoplasmic Reticulum Stress-mediated Programmed Cell Death in Arabidopsis. J Biol Chem 283: 3200-3210.

48. Isbat M, Zeba N, Kim SR, Hong CB (2009) A BAX inhibitor-1 gene in Capsicum annuum is induced under various abiotic stresses and endows multi-tolerance in transgenic tobacco. J Plant Physiol 166: 16851693.

49. Oshima R, Yoshinaga K, Ihara-Ohori Y, Fukuda R, Ohta A, Uchimiya $\mathrm{H}$, Kawai-Yamada M (2007) The Bax Inhibitor-1 needs a functional electron transport chain for cell death suppression. FEBS Lett 581: 4627-4632.

50. Hur Y, Hwang DJ, Zoubenko O, Coetzer C, Uckun FM, Tumer NE (1995) Isolation and characterization of pokeweed antiviral protein mutations in Saccharomyces cerevisiae: identification of residues important for toxicity. Proc Natl Acad Sci USA 92: 8448-8452.

51. Hudak KA, Parikh BA, Di R, Baricevic M, Santana M, Seskar M, Tumer NE (2004) Generation of pokeweed antiviral protein mutations in Saccharomyces cerevisiae: evidence that ribosome depurination is not sufficient for cytotoxicity. Nuc Acids Res 32: 4244-4256.

52. Büttner S1, Ruli D, Vögtle FN, Galluzzi L, Moitzi B, Eisenberg T, Kepp O, Habernig L, Carmona-Gutierrez D, Rockenfeller P, Laun P, Breitenbach M, Khoury C, Fröhlich KU, Rechberger G, Meisinger C, Kroemer G, Madeo F (2011) A yeast BH3-only protein mediates the mitochondrial pathway of apoptosis. EMBO J. 30(14):2779-92.

53. Oberhammer F, Wilson JW, Dive C, Morris ID, Hickman JA, E WA, Walker PR, Sikorska M (1993) Apoptotic death in epithelial cells: cleavage of DNA to 300 and/or $50 \mathrm{~kb}$ fragments prior to or in the absence of internucleosomal fragmentation. EMBO J 12: 3679-3684.

54. Ucker DS (1991) Death by suicide: one way to go in mammalian cellular development? New Biol 3: 103-109.

55. Madeo F, Herker E, Wissing S, Jungwirth $\mathrm{H}$, Eisenberg $\mathrm{T}$, Fröhlich $\mathrm{K}$ U (2004) Apoptosis in yeast. Curr Opin Microbiol 7: 655-660.

56. Takayama S, Sato T, Krajewski S, Kochel K, Irie S, Milian JA, Reed JC (1995) Cloning and functional analysis of BAG-1: A novel Bcl-2-binding protein with anti-cell death activity. Cell 80: 279-284.

57. Ligr M, Madeo F, Fr^hlich E, Hilt W, Fr^hlich K-U, Wolf DH (1998) Mammalian Bax triggers apoptotic changes in yeast. FEBS Lett 438 : 61-65.

58. Suzuki K, Nakamura M, Hatanaka Y, Kayanoki Y, Tatsumi H, Taniguchi N (1997) Induction of Apoptotic Cell Death in Human Endothelial Cells Treated with Snake Venom: Implication of Intracellular Reactive Oxygen Species and Protective Effects of Glutathione and Superoxide Dismutases. J Biochem 122: 1260-1264.

59. Jabs T (1999) Reactive oxygen intermediates as mediators of programmed cell death in plants and animals. Biochem Pharm 57: 231245.

60. Madeo F, Fröhlich E, Ligr M, Grey M, Sigrist SJ, Wolf DH, Fröhlich K$U$ (1999) Oxygen Stress: A Regulator of Apoptosis in Yeast. The J Cell Biol 145: 757-767.

61. Parikh BA, Coetzer C, Tumer NE (2002) Pokeweed Antiviral Protein Regulates the Stability of Its Own mRNA by a Mechanism That Requires Depurination but Can Be Separated from Depurination of the alpha-Sarcin/Ricin Loop of rRNA. J Biol Chem 277: 41428-41437.

62. Frey S, Pool M, Seedorf M (2001) Scp160p, an RNA-binding, Polysome-associated Protein, Localizes to the Endoplasmic Reticulum of Saccharomyces cerevisiae in a Microtubule-dependent Manner. J Biol Chem 276: 15905-15912. 
63. Parikh BA, Baykal U, Di R, Tumer NE (2005) Evidence for RetroTranslocation of Pokeweed Antiviral Protein from Endoplasmic Reticulum into Cytosol and Separation of Its Activity on Ribosomes from Its Activity on Capped RNA.. Biochem 44: 2478-2490.

64. Di R and Tumer NE (2005) Expression of a Truncated Form of Ribosomal Protein L3 Confers Resistance to Pokeweed Antiviral Protein and the Fusarium Mycotoxin Deoxynivalenol. MPMI 18 (8): 762-770.

65. Nicolas E, Beggs JM, Haltiwanger BM, Taraschi TF (1998) A New Class of DNA Glycosylase/Apurinic/Apyrimidinic Lyases That Act on Specific Adenines in Single-stranded DNA. J Biol Chem 273: 1721617220.

66. Fahrenkrog B, Sauder U, Aebi U (2004) The S. cerevisiae HtrA-like proteinNma111p is a nuclear serine protease that mediates yeast apoptosis. J Cell Science 117: 115-126.

67. Atlas RM (2002) BIOTERRORISM: From Threat to Reality. Ann Rev Microbiol 56: 167-185.

68. Brigotti $M$, Alfieri R, Sestili $P$, Bonelli $M$, Petronini $P$, Guidarelli A, Barbieri L, Stirpe F, Sperti S (2002) Damage to nuclear DNA induced by Shiga toxin 1 and ricin in human endothelial cells. The FASEB J 16: 365-372.

69. Rao PVL, Jayaraj R, Bhaskar ASB, Kumar O, Bhattacharya R, Saxena P, Dash PK, Vijayaraghavan $R$ (2005) Mechanism of ricin-induced apoptosis in human cervical cancer cells. Biochem Pharm 69: 855-865.
70. Xu Q, Reed JC (1998) Bax Inhibitor-1, a Mammalian Apoptosis Suppressor Identified by Functional Screening in Yeast. Mol Cell 1: 337-346.

71. Xu Q, Jürgensmeier JM, Reed JC (1999) Methods of Assaying Bcl-2 and Bax Family Proteins in Yeast. Methods 17: 292-304.

72. Parikh BA, Tumer NE (2004) Antiviral Activity of Ribosome Inactivating Proteins in Medicine. Mini-Rev Medicin Chem 4: 523-543.

73. Parikh B, Tortora A, Li X-P, Tumer N (2008) Ricin Inhibits Activation of the Unfolded Protein Response by Preventing Splicing of the HAC1 mRNA. J Biol Chem: 6145-6153.

74. Cakir B (2012) Bax induces activation of the unfolded protein response by inducing HAC1 mRNA splicing in Saccharomyces cerevisiae. Yeast 29(9):395-406.

75. Cebulski J, Malouin J, Pinches N, Cascio V, Austriaco N (2011) Yeast Bax Inhibitor, Bxi1p, is an ER-localized protein that links the unfolded protein response and programmed cell death in Saccharomyces cerevisiae. PLoS One 6(6):e20882.

76. Hudak KA, Dinman JD, Tumer NE (1999) Pokeweed Antiviral Protein Accesses Ribosomes by Binding to L3. J Biol Chem 274: 3859-3864.

77. Otto J, Lee S-W (1993) Immunoprecipitation methods. Methods Cell Biol 37119-37126. 